\title{
Population Control:
}

\section{Financial Incentives, Freedom, and Question of Coercion}

ABSTRACT: The planet's swiftly growing population coupled with the lack of food security and the degradation of natural resources has caused many demographers to worry about the ramifications of unchecked population growth while many philosophers worry about the ethical issues surrounding the methods of population control. Therefore, I intend to argue a system of encouraging a decrease in personal fertility rate via financial incentives offers a solution that is both viable and not morally reprehensible.

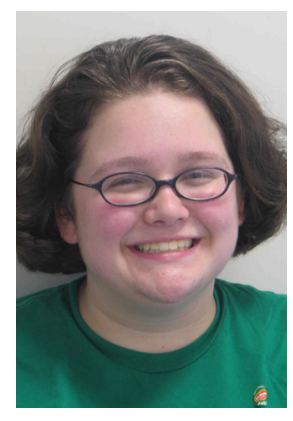

\begin{abstract}
Alicia M. R. Donner attends Creighton University in Omaha, Nebraska, where she is a senior. She is majoring in Environmental Sciences with a minor in Justice and Peace Studies. Her major philosophic interests are in the realm of environmental ethics. This fall, she will be participating in the Pittsburgh Urban Leadership Service Experience.
\end{abstract}

I ntroduction

As the global population climbs swiftly toward seven billion, concerns have risen regarding whether the planet can healthily sustain an ever-increasing population-and for good reason. From an environmental perspective, the earth simply cannot support the burgeoning numbers. This can be perceived when one considers the lasting effects of the Green Revolution; methods that have succeeded in creating the food surplus that the planet and its inhabitants enjoy have also succeeded in degrading many natural systems to a point at which it is no longer certain if they will recover, or will even continue to produce the food the world depends on at current levels into a foreseeable future. ${ }^{1}$

Emboldened by this odious fact and others, many have set out to formulate an ideal method to curb population growth. Those who advocate population control fall into two camps: doomsdayers and cautious optimists. Doomsdayers like Garrett Hardin advocate strict social sanctions on procreative rights. Though intended to end the population crisis

1. Paul Roberts, The End of Food (New York: Houghton Mifflin, 2008): xxi. 
with an urgency well suited to its namesake, these limitations on personal freedoms bother more people than just the average libertarian. Furthermore, aggressive and coercive strategies of population control tend not to pan out in the long run, as those repressed try to assert their freedoms and skirt the policies. ${ }^{2}$

At the other end of the spectrum lie the cautious optimists such as philosopher Clark Wolf, who seek to curb population growth while maintaining personal freedoms through the use of social incentives, such as educational and economic opportunities and an increase in social security. Although this option may seem like a reasonable solution, experience shows that relying strictly on voluntary methods has been only minimally successful and slow going, especially when the preferred family size remains higher than the necessary replacement rate. $^{3}$

Therefore, I intend to argue for a solution that is a compromise between these two extremes: using financial incentives to encourage a decrease in fertility, making smaller families more appealing, and increasing social programs. As a method of population control, this solution ensures individual freedoms while achieving the desired goal of population stabilization or even decrease.

\section{Financial Incentives}

As Bernard Berelson has remarked, money proves to be a very powerful motivator. ${ }^{4}$ In the realm of population control, money can be used as motivation in a variety of ways. Therefore, what is intended by my use of the phrase financial incentives needs to be clarified. Traditionally, the most common kind of financial incentives used in family planning programs have been small payments, often one time, to persons who undergo sterilization or choose to participate in some other form of birth control. ${ }^{5}$ These are not the type of financial incentives I intend to recommend.

Rather, I think financial incentives in the form of income tax credits for individuals who choose to limit their family size, or incentives in the broader category of those which improve welfare both on an individual and community level, would be a better motivation to curb family size. In theory, both types of incentives serve to use money as a motivator to make small families ideal. The income tax credit incentive would achieve this end by transforming the current pro-natalist tax system to one that is more neutral. ${ }^{6}$ This could be accomplished by offering a credit for the first, or even second, child but by cancelling credits for children that exceed this number.

Although this form of income tax credit incentive would be more applicable in the highly structured tax systems that exist in the West, the second form of incentives-those that are welfare oriented- exist in a variety of forms in both developing and more developed countries. The 1960s and 1970s saw an increase in population control programs, many of which

\footnotetext{
2. Clark Wolf, "Population and the Environment," in Environmental Ethics: Readings in Theory and Application, ed. Louis P. Pojman and Paul Pojman (Belmont: Thomson Wadsworth, 2008): 439.

3. Garret Hardin, "2. Multiple Paths to Population Control," Family Planning Perspectives 2.3 (1970): 26.

4. Bernard Berelson, “An Evaluation of the Effects of Population Control Programs," Studies in Family Planning 5.1 (1974): 2.

5. Judith Jacobsen, Promoting Population Stabilization: Incentives for Small Families (Washington: Worldwatch Institute, 1983 ): 7.

6. Edward Pohlman, Incentives and Compensations in Birth Planning (Chapel Hill: Carolina Population Center, 1971): 48.
} 
utilized monetary incentives, especially of the latter form discussed above.

Two programs in developing countries, the "Taiwan Educational Bond Scheme" and the "Tamil Nadu Tea Estate Program," proved to be both successful and improve welfare, although this welfare was directed more toward the individual families participating in the program rather than society as a whole. Both programs involved setting up a savings account for families or women enrolled, and continuance in the program was dependent on their reduced fertility.

For Taiwanese parents, the account, which was intended to pay for the education of two children through high school, would be halved upon the birth of a third child and cancelled if a fourth child was born. In Tamil Nadu, the account would be forfeited upon the birth of a fifth child. Even with these severe penalties, both programs were successful. In Taiwan, 75\% of eligible women enrolled and contraception practice rose from 19 to $31 \%$. In the first ten months of the Tamil Nadu program only two pregnancies were reported of the $90 \%$ of eligible women who chose to participate. ${ }^{7}$

One example of such a program in a Western nation, the United States, was the "Children's Opportunity Money and Environment" ("COME") program. With regard to the "COME" program, the government would use money not spent on children because a family had limited its size in allocations that would benefit those adults who chose not be parents. The cost of such incentives for the government and society is minimal when compared to the money saved per woman choosing not to have a child: in 1965 North Carolina, an average avoided birth would save society around $\$ 3,187.8$

Not only do programs like "COME" help encourage a decrease in fertility rates, they save society money, which can be used to fund other things, such as social programs. In the "Taiwan Educational Bond Scheme" and the "Tamil Nadu Tea Estate Program," this money is not given to the state, but is instead given directly to the citizen with the intent to improve welfare. This illustrated especially well through the Taiwanese program which was meant to increase educational opportunities for future generations.

Further, according to Judith Jacobsen, when considering the two kinds of programs with incentives that improve welfare, the intent behind these incentives can be understood not only as the lowering of fertility but also increasing wealth:

\begin{abstract}
The first [individual] involves periodic payments to an account or fund for people who limit their families. Payments can take the form of old-age pensions, life insurance, education funds and the like, and are collected in the future, when people have succeeded in having a small family. The second kind of program rewards whole communities with development projects that raise incomes as fertility in the community falls. ${ }^{9}$
\end{abstract}

Unlike the traditional form of incentives, which offer compensation to those who choose to

7. Berelson, "An Evaluation," 6.

8. Pohlman, Incentives and Compensations, 47-51.

9. Jacobsen, Promoting Population Stabilization, 14. 
become sterilized or participate in other forms of birth control, these more innovative incentives that promote general welfare reward persons for changes in behavior. From this perspective of understanding these incentives as rewards, one can begin to appreciate them not only as freedom enhancing versus freedom limiting, but also as a means to foster social change.

\section{Freedom}

When considering individual freedoms with regard to reproductive rights, one can view the system of incentives that offers rewards as a freedom's enhancement rather than the limitation of simple compensation:

\footnotetext{
...unlike one-time payments, rewards are made for behavior over a long period of time that requires deliberate thought, avoiding the lastminute pressure that can be present in one-time payments. Thus, deferred payment programs pose less risk of unfair influence. ${ }^{10}$
}

The more traditional forms of incentives are often accused of being coercive, especially in a psychological sense; a person may feel forced by the financial incentive to make a rash choice, without being fully aware of what he/she is agreeing to and how it will affect him/her. These circumstances may exacerbate a sense of exploitation where a person's poverty is dire and the compensation is comparatively great. ${ }^{11}$
This trend is further illustrated by incidents of sterilization regret. In a 1989 study of women in Sri Lanka who underwent voluntary sterilization between the years of 1980 and 1983 and were compensated for the procedure, $14 \%$ regretted the procedure, and of those who regretted the procedure, $85 \%$ regretted it because they wanted more children. ${ }^{12}$

These results are not only telling in relation to the possible coercive nature of certain methods of incentives to reduce fertility but also in showing that, even with the emphasis on reduced fertility through birth control, the underlying issue related to the world's population problem - that the ideal family size exceeds the size needed for population stabilization-still remains. ${ }^{13}$ To exacerbate the problem further, the ideal family size does not match up with the actual number of children born-the reality usually exceeds the ideal: according to a 1990 survey of 48 developing nations, the estimated "wanted" total fertility rate was 3.8 , more than a child less than the actual total fertility rate of 5.0. ${ }^{14}$ Even though birth control and family planning initiatives have been put into action, there is no social change. The traditional mindset which favors larger families remains, although it has been pushed aside.

On the other hand, the systems that offer rewards foster social change in the form of modified behavior, i.e. smaller family size. Further, the money goes to the individual or her community in the form of funding for social

10. Ibid

11. Ibid., 10.

12. Dennis Hapugalle et al, "Sterilization Regret in Sri Lanka: A Retrospective Study," International Family Planning Perspectives 15.1 (1989): 22, 27.

13. Hardin, "2. Multiple Paths," 24; Jacobsen, Promoting Population Stabilization, 6.

14. Hardin, "2. Multiple Paths," 24; Jacobsen, Promoting Population Stabilization, 6. 
programs mentioned above-much like those that the cautious optimists would favor from the start. ${ }^{15}$ Wolf advocates that the best way to reduce fertility is to foster development, especially in poorer countries. ${ }^{16}$ Berelson would agree with Wolf's assessment but would also express concern about the implementation of developmental policies:

The institutional factors are so "large" that they are not moved quickly or easily..."The point is less that such measures are uncertain of success, than that they cannot be achieved: the policies are reasonably clear, their early implementation is impossible." Thus it is relatively easy to prescribe for a lower birth rate in India and inordinately hard to achieve it in that way. ${ }^{17}$

However, a program utilizing financial incentives would be more than just a prescription for development-it would hasten the process. This is especially true of programs that seek to improve welfare, as one of the benefits of the incentives is increased wealth available for reinvestment in the community.

Furthermore, Jacobsen lists pensions, life insurance, and education as where money collected in welfare programs go, all of which correspond to at least one of the three collaborative measures for fertility reduction that Wolf lists. ${ }^{18}$ These measures involve an increased opportunity cost to have children:
1. Efforts to expand women's educational opportunities.

[...]

3. Since the need for old-age security is a prime incentive to have children in most developing countries, institutions that increase the economic security of the elderly remove an important destructive incentive to have children. ${ }^{19}$

Financial incentives which exist to promote welfare not only decrease fertility in and of themselves, but because they can encourage social change and social programs, they can also instigate the beginnings of development, creating a cycle which will further reduce fertility and continue to feed off of itself.

\section{Criticism of Financial Incentives}

Garrett Hardin would be rather critical of my argument, especially concerning the viability of tax credits as an incentive. This is evident in the second stage of the method he suggested to reduce fertility in the United States in the 1970s-one that is not exploitive but at the same time is not explicitly dependent on voluntary methods. Here, Hardin proposed a modification of income tax laws, but not because they have any viability as a financial incentive for either the citizen or the state:

[Modifying the income tax law] won't save the nation money any more than it will serve as an

15. Jacobsen, Promoting Population Stabilization, 14.

16. Wolf, "Population and the Environment," 440.

17. Berelson, "An Evaluation," 4.

18. Jacobsen, Promoting Population Stabilization, 14.

19. Wolf, "Population and the Environment," 439.20. Hardin, "2. Multiple Paths," 26. 
for parents to have less children. Such tax laws would, however, have a symbolic effect: They will indicate that the nation doesn't want parents to have more than two children.... ${ }^{20}$

He does not view the financial incentive method concerning taxes practical in any way, he only mentions it as a secondary, symbolic incentive. For him, using tax credit incentives to decrease fertility does not make sense, but using social pressures does.

\section{Coercion}

Besides orchestrating social pressure, another criticism of coercion can be raised. There is a fine line between offer and threat, and in the realm of reproductive rights it seems all the more narrow. Hardin, showing his true colors as a doomsayer, admits that if it is deemed necessary to solve the problem of overpopulation, he would not have a problem using coercion in the form of non-voluntary methods. ${ }^{21}$ Berelson describes the doomsayer's assessment as such: ...in response to the perceived crisis, [doomsayers] consider that childbearing is not a right but a privilege to be conferred or not by the state- to be managed, like death control, for the good of all. ${ }^{22}$ This assessment is very similar to Hugh LaFollette's assertion that parents should be licensed, although the aims of both differ.
LaFollette's main aim in licensing parents would be to end the mistreatment of children; population control would prove a fortunate side effect of such a policy. ${ }^{23}$ Even so, for the time being, Hardin believes that voluntary and therefore non-coercive methods should be the primary ones. ${ }^{24}$

Bonnie Steinbock reminds the reader that society cannot function without some degree of coercion: the system of taxation that a nation depends on for revenue or the required immunizations that protect the health of the public are both instances of coercion. Further, Berelson notes that coercion is accepted for two of the three major transitions that fuel demographic growth, mortality and migration, but not the third, fertility. He remarks that citizens rely on the state to maintain public health standards and monitor immigration for the common good but do not depend on or even seek the state's judgment when it comes to how many children a family should have, even though logically these limitations would be analogous to bans on bigamy. ${ }^{25}$

In some ways, any form of incentive that makes a person consider an alternative that she had not considered before can be viewed as coercive, even if it proves to enhance rather than hinder a person's rights. ${ }^{26}$ Even so, Steinbock remains incredibly vigilant about the dangers of

20. Hardin, "2. Multiple Paths," 26.

21. Ibid.

22. Berelson, "An Evaluation," 3.

23. Hugh LaFollette, "Licensing Parents," in Environmental Ethics: Readings in Theory and Application, ed. Louis P. Pojman (Belmont, CA: Thomson Wadsworth, 2005): 395.

24. Hardin, "2. Multiple Paths," 26.

25. Berelson, "An Evaluation," 3.

26. Bonnie Steinbock, "Coercion and long-term contraceptives," Hastings Center Report 25.1 (1995): S19. Academic Search Premier. EBSCO. Reinert-Alumni Memorial Library, Omaha, NE. 11 Dec. 2008. https://login.cuhsl.creighton.edu/login?url=http://search.ebscohost. $\mathrm{com} /$ login. aspx ?direct=true \&db=aph\&AN=9502217612\&loginpage=login. asp \&site=ehost-live. 
exploitation: "[...]focusing entirely on whether programs like those to encourage contraception are coercive may mask other important objections to such programs, such as their targeting of vulnerable groups, creating and reinforcing inequality." 27

It is important to realize that coercion does have a place in how society functions but, at the same time, exploitation does not. This is definitely a challenge in the realm of population control as it is predominantly poorer countries with higher rates of fertility that are being studied and acted upon by Western demographers and ethicists. It also proves to be a pertinent observation when one considers the encouraging development method of population control, especially if tied in with financial incentives to speed up said development: with accelerated development comes the accelerated and exacerbated problems of development. These problems include disrupting existing cultures and social systems, the problems of crowding and slums that are associated with urbanization as well as an overall increase in consumption. ${ }^{28}$ These disadvantages are important to recognize and plan for accordingly, and it needs to be decided how they compare to the advantages created by population control.

In the grand scheme of things, all members of society-regardless of their place in the cosmic food chain-should be able to influence each other for the benefits of everyone in that society. This is how society is designed to function, with its members providing a system of checks and balances in the form of influence. How this model will weather the current, swiftly moving trend toward globalization and the melding of many different societies and cultures that it entails is, unfortunately, a subject for another paper.

\section{Conclusion}

Hardin, Steinbock, Berelson and Claudia Mills bring up challenging points, especially those concerning the real role of tax incentives and the role of coercion and its place in population control efforts. First, Hardin's comments regarding the fact that tax incentives are not financially viable and are only symbolic bring up a good point, even though I disagree with the idea that the tax incentives have no financial effect. I believe it is the financial incentive for the state and individual that encourages these programs to be put in place at all. In addition, these financial incentives can prove to encourage social change. Therefore, these incentives can also be symbolic. The way financial incentives are used regarding population control efforts can act as a herald of what changes lie just beyond the horizon.

Coercion presents a stickier issue. When I first began this paper, I interpreted coercion as exploitation. And, as Steinbock reminds the reader, exploitation is something dangerous and to be avoided. Now, coercion has taken on new light as a necessary tool in the viable functioning of society. I agree with Hardin that, as long as possible, we should avoid depending

27. Steinbock, "Coercion."28. Margaret Pabst Battin, "Population Policies, Strategies for Fertility Control in," in Encyclopedia of Bioethics, Ed. Stephen Post. Vol. 4, (New York: Macmillan Reference USA, 2004), 2096.

28. Margaret Pabst Battin, "Population Policies, Strategies for Fertility Control in," in Encyclopedia of Bioethics, vol. 4, ed. Stephen Post (New York: Macmillan Reference USA, 2004): 2096. 
strictly on coercive methods because of the unfortunate trend of their abuse. At the same time, however, it does not seem like any form of population control can be accomplished without coercion in some form.

As a method of encouraging population control, the use of financial incentives to make smaller families more appealing, as well as encouraging social change, would reduce population more quickly without the problems associated with strictly repressive and potentially exploitive anti-natalist policies. Coercion, understood as non-voluntary but also non-exploitive, may be necessary in order to really bring population growth rates under control through the use of financial incentives, which is not strictly viewed as a doomsdayer approach.

This approach may prevent the solid guarantee of the protection of individual freedoms, but the loss of a few freedoms would only occur so that a world would be guaranteed for future generations, especially generations that do not lie too far off. More importantly, coercion in this manner highlights that the only way population control will be achieved is through international cooperation-global citizens holding each other accountable in order to attain a better home for us all. 